\title{
POLÍTICAS DA EDUCAÇÃO SUPERIOR NO BRASIL (2003-2010): DEMOCRATIZAÇÃO OU EXPANSÃO?
}

\author{
$*$ \\ Adrian Alvarez \\ Universidade Estadual do Oeste do Paraná - Unioeste - Brasil \\ Andressa Benvenutti Radaelli \\ Universidade Estadual do Oeste do Paraná - Unioeste - Brasil
}

\section{Resumo}

Objetiva-se com este trabalho discutir sobre o processo de expansão da educação superior no Brasil. Nesse sentido, procuramos revisar pontos determinantes e elementos caracterizadores do Programa de Apoio a Planos de Reestruturação e Expansão das Universidades Federais (REUNI) refletindo sobre o acesso à universidade pública. Para isso realizamos uma breve discussão sobre Estado e políticas públicas, em especial as políticas para a educação superior, levando-se em consideração a relação estabelecida entre tais elementos e resgatando os determinantes desse movimento e suas particularidades. Buscamos analisar as políticas educacionais voltadas para a educação superior durante o governo Fernando Henrique Cardoso (FHC) e Lula, no que diz respeito ao acesso, bem como seus elementos norteadores. Essa contextualização leva em consideração, que a educação não pode ser considerada como fenômeno neutro e, portanto, decorre da intervenção do Estado, e os efeitos do espaço no qual está inserido. As análises indicam que o processo de reformas para a educação superior implementadas no Brasil, principalmente no âmbito do REUNI está impregnado de objetivos ideológicos, ações e contradições que se estabelecem em relação aos pressupostos teóricos e práticos, apresentando elementos que ao mesmo tempo resultam na reforma do Estado e buscam dar sustentação aos interesses sociais.

Palavras-Chave: Expansão; Democratização; Educação Superior.

\section{Introdução}

Como nos demais setores da sociedade, pela ordem capitalista, a política educacional reflete as transformações sociais e possui, portanto, influência direta das relações entre Estado e Sociedade. Dessa forma, levando em consideração o contexto político, social, econômico em que se encontram, as políticas educacionais brasileiras são regularmente definidas pelo Estado como produto dos embates sociais. Assim, consideramos importante a análise das ações propostas pelo Estado no processo de elaboração da política educacional, principalmente sobre seu papel na educação superior, especialmente às políticas de acesso.

A legislação brasileira especialmente a Carta Magna concebe a educação como direito social. Contudo, o Brasil ainda é um país que apresenta índices desproporcionais quanto ao 
acesso ao sistema educacional, especialmente no que se refere a educação superior. A necessidade de expansão desse nível de ensino é visível, tendo em vista que na média nacional, apenas $24,3 \%$ dos jovens brasileiros, com idade entre 18 e 24 anos, tem acesso à educação superior (BRASIL, 2008).

Nesse processo, foram adotadas uma série de medidas estabelecendo diretrizes para expansão do Sistema Público Federal de Educação Superior. Sendo assim, consideramos fundamental debater os principais elementos quanto à expansão do acesso proposto pelo Programa de Apoio a Planos de Reestruturação e Expansão das Universidades Federais (REUNI), desenvolvido durante o Governo Lula. Instituído pelo decreto 6.096 de 24 de abril de 2007 , em seu artigo $1^{\circ}$, afirma que "tem por objetivo criar condições para ampliação do acesso e da permanência na Educação Superior” (REUNI, 2007).

Com base nas questões elencadas, para compreendermos o atual contexto em que a educação superior está inserida é fundamental analisar os reflexos das políticas educacionais desenvolvidas até então e seus desdobramentos no processo de ampliação do acesso. Tecemos considerações sobre a relação entre Estado e sociedade no processo de desenvolvimento das políticas públicas e a relação destas com as políticas educacionais. Realizamos uma breve análise dos governos Fernando Henrique Cardoso (FHC), que compreendeu os períodos de 1994 a 2002 e os anos de 2003 a 2012 que compreenderam o governo Lula, com o objetivo de verificar continuísmos e rupturas nas políticas para educação superior.

Entendemos que a compreensão desses conceitos contribui para a construção de um quadro teórico sobre o cenário em que se apresentam as políticas públicas para a educação superior no Brasil em especial as políticas de acesso, principalmente por meio do REUNI.

\section{Considerações sobre Políticas Públicas e Políticas Educacionais}

No âmbito desse debate, o Estado se constitui uma categoria fundamental de análise, principalmente por o entendermos como ativo no processo de contradições oriundas da dinâmica social e preconizador das políticas públicas. Diante do exposto, nesta seção mais do que tratar da definição e conceitualização de Estado, consideramos importante compreender as políticas públicas a partir das relações entre este e sociedade. Realizaremos a seguir uma abordagem sobre Estado e políticas públicas, tecendo considerações acerca do entendimento que se adota.

A partir dessa compreensão podemos inferir que a função do Estado está nas relações políticas, econômicas e sociais que se embatem na sociedade. Assim, é impossível pensar em 
Estado sem tratar de seu aspecto produtor, reprodutor e regulador das políticas públicas por ele desenvolvidas. Nesse sentido, para Faleiros (2006, p.57) “o Estado não se encontra fora ou acima da sociedade, mas é atravessado pelas forças e lutas sociais que condicionam a articulação das exigências econômicas e dos processos em cada conjuntura". Desse modo, as políticas ao serem desenvolvidas só podem ser pensadas quanto às relações em sociedade e como parte das respostas qualificadas do Estado à questão social.

De todo modo, o Estado sempre foi um agente fundamental no desenvolvimento das políticas públicas, sendo este movimento articulado ao modo de produção capitalista e a luta de classes. Shiroma (2011, p. 07) apresenta o seu entendimento sobre as políticas públicas, onde,

Reporta-se, fundamentalmente, à atividade ou ao conjunto de atividades que, de uma forma ou de outra, são imputadas ao Estado moderno capitalista ou dele emanam. $\mathrm{O}$ conceito de política encadeou-se, assim, ao do poder do Estado - ou sociedade política - em atuar, proibir, ordenar, planejar, legislar, intervir com efeitos vinculadores a um grupo social definido e ao exercício do domínio exclusivo sobre um território e da defesa de suas fronteiras.

As políticas públicas têm a sua dinâmica desenvolvida de acordo com o contexto social a qual estão inseridas e as demandas dela emanadas, por isso devem ser a expressão do interesse proposto pela sociedade, e a esse respeito, Zanardini (2006, p. 7) caracteriza as políticas públicas como ações específicas do Estado num processo de consolidação de um projeto de sociedade.

As políticas públicas são datadas historicamente, construídas por sujeitos concretos e que têm por fim a consolidação de um projeto social, político e econômico específico, refletindo as forças políticas em jogo, como resultado de pressões exercidas pelas classes em luta. Logo, as políticas públicas não se reduzem a um conjunto de ideias, nem a setores específicos, mas são amplas e implicam a elaboração de estratégias de ação capazes de implementar um conjunto de reformas ou de propostas necessárias à sobrevivência de um determinado modelo social, político e econômico.

Diante do exposto, é importante destacar que o processo de elaboração e implementação de políticas públicas não são, pois, uniformes, estáticos ou permanentes, o que pressupõe refletir as contradições existentes nas relações sociais, Faleiros (2006, p.60) estabelece nesse contexto que "a análise da conjuntura política ou da correlação de forças num momento determinado é assim fundamental para compreensão das políticas sociais”. Em face do exposto, cabe refletir que o Estado é organizador, executor e garantidor das políticas públicas, logo, suas ações são frutos da luta entre classes sociais, portando, são aqui compreendidas como responsabilidade do Estado. 
A partir do entendimento da relação entre Estado e sociedade a abordagem a seguir visa trazer elementos que contribuam para a compreensão das políticas públicas desenvolvidas pelo Estado, destacando a abordagem educacional. Ao analisar a política educacional partimos do pressuposto que estas compõem um conjunto de políticas sociais implementadas no contexto de uma sociedade marcada pela luta de classes. Partindo desse pressuposto, compreende Deitos (2010, p. 209), que a política educacional:

É entendida aqui como constituinte da política social. As políticas públicas diretamente definidas e dirigidas pelo Estado são compreendidas como o resultado de mediações teórico-ideológicas e socioeconômicas e estão diretamente imbricadas no processo de produção social da riqueza e, consequentemente, de sua repartição e distribuição. A política educacional, particularmente a empreendida no Brasil a partir a década de 1990, é a articulação e a consumação de forças econômicas e políticas hegemônicas que sustentam proposições que revelam forte tendência predominante de cunho liberal ou social-liberal e definem significativamente os rumos das políticas públicas e da educação nacional.

Assim, a política educacional é um componente do processo de produção e reprodução social e, conforme trata Deitos (2010) é inserida num conjunto de políticas e medidas tomadas para assegurar a hegemonia de um dado projeto social, político e econômico socialmente em disputa e concretiza aquilo que se quer constituir na sociedade, ora com o intuito de amenizar alguns problemas sociais, ora com o objetivo de garantir o consumo de mercadoria. Nagel (2001, p.99) trata a política educacional como "um conjunto de medidas agilizadas e sistematizadas pelo Governo para atuar, com maior eficiência, nos mecanismos de produção, distribuição e consumo de bens já instituídos ou em constante renovação".

Esta segunda orientação tem conduzido a política educacional para a educação superior se concentrar em processos que auxiliam no acesso e a permanência de grupos mais vulneráveis. E conforme estabelece Finatti (2007, p.16),

\footnotetext{
O papel do Estado na Política de Educação Superior é expresso quando se define como poder, que legitima a forma de acesso e qualidade; quando promove equidade social nos processos seletivos; quando se responsabiliza pela manutenção das instituições de ensino superior públicas; quando promove uma gestão participativa; quando se coloca como autorizador para o funcionamento das instituições privadas; e quando é responsável pela avaliação através do Sistema Nacional de Avaliação Institucional.
}

É necessário nesse estudo considerar como pressuposto que, as políticas educacionais vêm sendo desenvolvidas como parte formadora do conjunto de exigências concebidas sob inspiração neoliberal. Partindo, portanto do pressuposto de que a concepção de políticas públicas está articulada ao Estado, e resultam da correlação de forças existentes entre as 
classes sociais.

\section{Educação Superior: a herança FHC e as ações de Lula}

Ao tratarmos da política educacional brasileira, levaremos em consideração como ponto fundamental de nossa análise, as ações governamentais no contexto da reforma do Estado capitalista e seus desdobramentos que se configuram na educação superior. A discussão sobre as políticas voltadas ao acesso à Educação Superior no Brasil nos conduz a recuperar não apenas questões ligadas às atuais políticas, mas possibilita reconstruir, mesmo que parcialmente, suas ligações com as concepções neoliberais. Portanto, para compreendemos as relações que expressam ações governamentais, abordaremos inicialmente algumas questões relevantes quanto ao cenário da política do Governo Fernando Henrique Cardoso - FHC (1995-2002), como parte constitutiva da Reforma do Estado, momento este em que as mudanças na educação superior se tornam mais evidentes e delinear as ações voltadas para a educação superior brasileira durante o Governo Luiz Inácio Lula da Silva, que compreendeu o período entre 2003 a 2010. Para tanto, A centralidade deste trabalho foca-se no governo Lula, pois este foi o responsável pelo projeto REUNI.

As ações do governo FHC apontaram em grande medida para a consolidação do projeto neoliberal a partir da expansão da educação superior através da rede privada e a ausência de investimentos nas universidades públicas. Portanto, como ponto de partida, adotamos a premissa de que um conjunto de medidas foram adotadas durante o período compreendido por esse governo, com vistas a diversificar as formas de financiamento e um amplo processo de adequação às exigências da economia mundial com base em um modelo que associa flexibilidade, competitividade e avaliação, e, principalmente por defender e preconizar o movimento de privatização como parte da estratégia de enfrentamento da crise de acumulação do capital.

Dado esse contexto, a análise da educação superior para esse período nos permite compreendê-lo a partir de uma lógica econômica e produtivista que implica uma remodelação do sistema, especialmente nas universidades federais. Diante dos elementos destacados, observa-se que esteve em curso a partir dos anos 1990, um conjunto de ações norteadas sob o viés liberal, um processo de diversificação e diferenciação, que ocasionou diferenças essenciais nas atividades, nos serviços e nas alternativas de solução para os problemas enfrentados na educação superior, apontando a necessidade de uma reforma que resultasse em racionalidade e eficiência ao sistema. 
Nesse período, no entendimento de Sguissardi (2000, p.47) “o binômio diversificaçãodiferenciação, isto é diferenciação institucional e diversificação das fontes de financiamento das Instituições de Ensino Superior (IES), integra o discurso e a prática das políticas e reformas da educação superior, no Brasil", ou seja, são entendidas como parte da solução para os males da educação superior. No entanto como esclarece Oliveira (2011, p.334) "as mudanças no papel do Estado, pretendidas pelas reformas educacionais nos anos de 1990, postulando maior desregulamentação e descentralização na gestão das políticas públicas sociais, não resultaram em maior eficiência".

Como consequência dessa política adotada pelo governo FHC, aponta Saviani (2010, p. 13) "freou-se o processo de expansão das universidades públicas, especialmente as federais, estimulando-se a expansão de instituições privadas com e sem fins lucrativos". A reorganização da educação superior parece ter uma finalidade clara, onde preza o ajustamento das universidades a uma nova orientação política e uma nova racionalidade técnica, o de transformar as universidades federais em organizações sociais, regidas por um contrato de gestão, que como tratam Catani e Oliveira (2000, p.71) no bojo desse processo de diversificação e diferenciação parte da ideia de que "essas instituições são ineficientes no uso dos recursos públicos, o que se coaduna com a orientação do Banco Mundial que inclui reduzir gradualmente, a aplicação de recursos públicos para o financiamento da educação superior".

Assim, é importante destacar, numa perspectiva de análise do contexto geral, que as políticas educacionais desenvolvidas durante o governo de FHC no entendimento de Cunha (2003) fazem parte processo de reforma da educação superior que já vinha sendo expressa pelo Grupo Executivo para a Reformulação da Educação Superior (GERES) em curso no Brasil em meados da década de 1980, e a partir do projeto de Reforma do Estado promovida pelo Ministério da Administração e Reforma do Estado (MARE), sob a coordenação do Ministro Luiz Carlos Bresser Pereira ${ }^{1}$ e consoante com critérios do mercado, que desencadeou orientações no processo de reformas, políticas e ações educacionais.

Nesse rumo, para eficiência do projeto burguês a política educacional nacional deve atender eficientemente aos preceitos ideológicos e às metas programáticas neoliberais, onde o

\footnotetext{
1 Emergiu o que o próprio ministro chamou de Estado Gerencial. O processo de reforma implantado compreendeu, entre outros aspectos, uma política de ajuste fiscal, maior autonomia dos gestores públicos e a utilização de formas expressas de redução de custos, entre as quais, a transferência para o setor público não estatal das atividades não exclusivas do Estado, campo de atuação do terceiro setor. De acordo com Bresser Pereira (2001) o pressuposto é o de modernizar a administração pública tornando-a eficiente sob os critérios do mercado, constituindo um Estado que seja adequado às necessidades da acumulação do capital. Tornando o Estado mais ágil, menos burocrático e clientelista, inspirada nos critérios de eficiência do mercado.
} 
estado deve implementar parcerias com o setor privado para o financiamento e implementação de políticas consideradas como setores não exclusivos do Estado ${ }^{2}$. De acordo com Lima (2006, p. 30),

É neste setor de atividades não exclusivas do Estado que está a educação superior. A partir de 1995, o governo Cardoso imprimiria uma determinada concepção de educação superior, entendendo-a como um conjunto complexo de instituições públicas e privadas, do qual as universidades são parte do sistema, mas que não devem responder a todas as demandas da sociedade. Esse discurso fundamentaria a política de privatização da educação superior, via diversificação das instituições e dos cursos, e diversificação de suas fontes de financiamento.

De acordo com Carvalho (2006, p. 127) "uma das críticas essenciais ao governo FHC é a ineficiência da universidade pública e sua inadequação ao mercado de trabalho". Nesse contexto de reformas, para esse governo, a universidade não era considerada uma instituição eficiente e competitiva, portanto não estava adequava aos anseios do mercado de trabalho, devendo, ser reformada.

De acordo com Lima (2006) o projeto de reformas estruturais e de configuração da educação como um serviço não exclusivo do Estado, atravessou o governo FHC e está sendo aprofundado no governo Lula através de uma nova geração de reformas neoliberais e acrescenta ainda:

\begin{abstract}
É fundamental, portanto, a compreensão de que a reformulação da educação superior em curso está inserida em um processo mais amplo de reordenamento do Estado capitalista. Um processo que atravessou o governo Cardoso e está sendo aprofundado no governo Lula pelo seguinte pressuposto básico: a educação está inserida no setor de serviços não exclusivos do Estado, o que reduz a alocação de verbas públicas para a política educacional, especialmente para a educação superior (LIMA, 2006, p.31-32).
\end{abstract}

Assim, as reformas que fizeram parte do governo FHC procuraram traduzir o discurso legitimado pela lógica do capital que atribuiu a crise da educação à ineficiência de aspectos específicos como gestão, e parte do princípio das mudanças econômicas em busca da maior

\footnotetext{
${ }^{2}$ O termo setor não exclusivo do Estado, ocorreu com a Reforma Gerencial do Estado de 1995 elaborado durante o Governo FHC, o qual propôs uma reestruturação estratégica na forma de gerenciamento do Estado a fim de torná-lo mais eficiente. Conforme Bresser Pereira (2001, p.32) "procurou criar novas instituições legais e organizacionais que permitissem a uma burocracia profissional e moderna ter condições de gerir o Estado brasileiro". Assim, os serviços prestados pelo Estado ficam divididos em três setores: o primeiro setor das atividades exclusivas que envolvem o poder do Estado, são de propriedade Estatal e dentro da qual estão o núcleo estratégico e as agências executivas ou reguladoras, o segundo grupo, encontram-se os serviços nãoexclusivos do Estado, referem-se aos serviços que demandam forte financiamento do Estado, mas também podem ser oferecidos pelo setor privado, são considerados de propriedade público não-estatal correspondem aos serviços sociais e científicos como educação e saúde, o terceiro grupo de produção de bens e serviços para o mercado, formado pelas empresas de propriedade privada, caracteriza-se pelas atividades econômicas orientadas para o lucro.
}

Barbarói, Santa Cruz do Sul, n.46, p.<217-232>,jan./jun. 2016 
eficiência e produtividade para o mercado tendo como base um processo de diversificação e diferenciação da educação superior para que esta possa se expandir e tornar-se mais ágil e dinâmica no atendimento e na produção de um saber interessado no sentido capitalista, tornando assim, as universidades organizações mais produtivas e pragmáticas.

Nesse contexto entendemos que o discurso marcado pelas diretrizes neoliberais e a valorização do processo de mundialização do capital atravessou o governo FHC e, em grande medida, permaneceu no Governo Lula (2003-2010). Portanto, a seguir, pretendemos analisar os principais elementos norteadores da política educacional para a educação superior durante o Governo Lula. Em 2003, Lula assumiu o poder e seu primeiro mandato foi caracterizado, no campo educacional, muito mais por permanências que rupturas e muitos autores a definem como continuidade do governo que o antecedeu. De acordo com Oliveira (2009, p.198),

Tendo sido herdeiro de uma reforma educacional de longo alcance e complexidade, que durante os dois mandatos do governo que o precedeu - FHC - mudou os rumos da educação brasileira do nível básico ao superior, restava a esse governo reformar a educação ou conservar e manter as iniciativas anteriores. A opção parece ter sido pelo segundo caminho.

Os contornos dessa política se apresentaram como um "aparente" novo modelo de desenvolvimento econômico e social, porém, não deixando o viés liberal no desenvolvimento de suas ações. Nesse processo, Boito Junior $(2006$, p. 7) compreende

\footnotetext{
O Governo Lula promoveu pequenas mudanças na política econômica e na política social que, embora não cheguem a alterar a dependência econômica e financeira da economia nacional e as condições de vida da população trabalhadora, poderão dar um novo fôlego político a esse modelo antinacional e antipopular de capitalismo.
}

Com relação à educação superior, a política começou a ser efetivamente construída de acordo com Aprile e Barone (2008), a partir da composição do Grupo de Trabalho Interministerial (GTI), instituído pelo Decreto de 20 de outubro de 2003, teve como objetivo diagnosticar a conjuntura da educação superior brasileira e apresentar um plano de ação visando reestruturação, desenvolvimento e ampliação das IFES.

O grupo sugeriu ações para enfrentar a crise atual das universidades federais e orientar o processo de reforma da universidade brasileira. E dentre as alternativas que, segundo orientações do GTI, resolveriam os problemas das IFES estavam: reposição do quadro docente, expansão e ampliação das vagas, educação à distância, autonomia universitária e refinanciamento da universidade pública, estabelecimento de uma nova regulação entre os sistemas público e privado (APRILE e BARONE, 2008). 
Nesse mesmo caminho, Lima (2007) destaca que a reforma da educação superior do governo Lula fundamenta-se em uma espécie de "relançamento requentado" das propostas privatizantes que os órgãos de financiamento internacionais e o governo neoliberal de FHC apresentaram ao longo da década de 90, só que agora, o discurso aparece maquiado com a ideia de um "novo humanismo". Portanto, para Lima as diretrizes da Reforma da Educação Superior do governo Lula foram determinadas pelos Organismos Internacionais, em grande parte pelas diretrizes que foram defendidas no documento realizado pelo GTI.

Diante do exposto e considerando o cenário de disputas, no decorrer do seu Governo, Lula definiu a trajetória das políticas para o alcance de suas metas. Como não estamos nos propondo a uma análise de cada uma das políticas implantadas, descreveremos brevemente a principal ação voltada para expansão da educação superior no Brasil, o REUNI.

\section{Educação Superior: REUNI e a expansão do acesso}

A despeito das mudanças ocorridas na educação superior, durante o governo Lula consideramos como parte fundamental e integrante do objeto de nossa análise as ações do seu discurso de ampliação do acesso à educação superior realizadas por meio do REUNI. Assim, nesse estudo, trataremos o processo de criação e interiorização de novas IFES, abertura de novas vagas, expansão do acesso à Educação Superior.

Instituído pelo Decreto $\mathrm{n}^{\circ}$ 6.096, de 24 de abril de 2007, o REUNI é uma das ações integrantes do Plano de Desenvolvimento da Educação (PDE) e tem como principal objetivo dotar as universidades federais das condições necessárias para ampliação do acesso e permanência na educação superior. Assim sendo, em seu Art. $1^{\circ}$ estabelece criar mecanismos que possibilitem a ampliação do acesso e permanência na educação superior, no nível de graduação, conforme Brasil (2007),

\footnotetext{
Art. $1^{\circ}$ Fica instituído o Programa de Apoio a Planos de Reestruturação e Expansão das Universidades Federais - REUNI, com o objetivo de criar condições para a ampliação do acesso e permanência na educação superior, no nível de graduação, pelo melhor aproveitamento da estrutura física e de recursos humanos existentes nas universidades federais.
}

Conforme Brasil (2007), o programa tem o objetivo de expandir, de forma significativa, as vagas para graduação no Sistema Federal de Educação Superior, ampliando o acesso e a permanência nesse nível de ensino. Com o REUNI, o governo federal adotou uma série de medidas para retomar o crescimento, criando condições para que as universidades federais promovam a expansão física, acadêmica e pedagógica da rede federal de educação 
superior.

As ações do programa contemplam desde o aumento de vagas nos cursos de graduação, a ampliação da oferta de cursos noturnos, a promoção de inovações pedagógicas e o combate à evasão, entre outras metas que têm o propósito de diminuir as desigualdades sociais no país, conforme Brasil (2007) em seu Art. $2^{\circ}$, as diretrizes para o REUNI foram estruturadas em seis dimensões, cada uma com um conjunto de aspectos específicos. Essas dimensões, conforme apresentadas a seguir, devem ser combinadas no plano de reestruturação das universidades federais, de acordo com a opção institucional em cada caso.

I - redução das taxas de evasão, ocupação de vagas ociosas e aumento de vagas de
ingresso, especialmente no período noturno; II - ampliação da mobilidade estudantil,
com a implantação de regimes curriculares e sistemas de títulos que possibilitem a
construção de itinerários formativos, mediante o aproveitamento de créditos e a
circulação de estudantes entre instituições, cursos e programas de educação superior;
III - revisão da estrutura acadêmica, com reorganização dos cursos de graduação e
atualização de metodologias de ensino-aprendizagem, buscando a constante
elevação da qualidade; IV - diversificação das modalidades de graduação,
preferencialmente não voltadas à profissionalização precoce e especializada; V -
ampliação de políticas de inclusão e assistência estudantil; e VI - articulação da
graduação com a pós-graduação e da educação superior com a educação básica.

O programa não preconiza a adoção de um modelo único para as universidades federais, nesse sentido, o Ministério da Educação destinará ao Programa recursos financeiros, que serão reservados a cada universidade federal, na medida da elaboração e apresentação dos respectivos planos de reestruturação, a fim de suportar as despesas decorrentes das iniciativas propostas conforme trata Brasil (2007),

I- construção e readequação de infraestrutura e equipamentos necessárias à realização dos objetivos do Programa; II- compra de bens e serviços necessários ao funcionamento dos novos regimes acadêmicos; e III- despesas de custeio e pessoal associadas à expansão das atividades decorrentes do plano de reestruturação.

Conforme consta em Brasil (2008), o Programa de Expansão da Educação Superior Pública, iniciado em 2003, adotou uma série de medidas qualificadas em três etapas, que teve seu início de implantação em 2008 e conclusão em 2012. No primeiro ciclo se daria a Expansão para o interior, com a criação de novas universidades federais e campi universitários; o segundo ciclo foi a expansão com reestruturação, que contou com a adesão das IFES e campi universitários já existentes para ampliação do número de vagas, especialmente no período noturno, e o terceiro ciclo baseava-se na criação de universidade federais em regiões territoriais estratégicas.

Cabe salientar, conforme consta em REUNI (2007), o processo de acompanhamento 
da execução das metas propostas pelas universidades será realizado por meio da Plataforma PingIFES ${ }^{3}$, cujo objetivo consiste na coleta de informações sobre a vida acadêmica das IFES. Seus dados são utilizados na distribuição dos recursos orçamentários para as universidades.

Abordaremos nas linhas que se seguem um breve panorama dos resultados do REUNI. Conforme dados do Instituto Nacional de Estudos e Pesquisas Anísio Teixeira (INEP, 2013), o número de IFES que era de 39 em 1995, em 2003 contava com 45 e passou para 59 em 2010. O número de municípios atendidos pelas universidades passou de 114 em 2003 para 237 até o final de 2011. Podemos verificar que houver um aumento do número de instituições e consequente aumento na oferta de vagas, porém ainda não é suficiente para afirmar que houve democratização de acesso.

O período de 2001 a 2010 é marcado não somente pelo aumento do número de IFES, mas também as instituições privadas. Conforme dados do INEP (2013), do total de instituições que em 2001 era de 1391 passa para 2.378 em 2010, 89,4\% são privadas (2.100) e apenas 10,6\% públicas (278). Outro dado relevante é referente ao quantitativo de universidades criadas, preexistentes e previstas, conforme dados REUNI (2007) entre 2003 e 2011. Em 2003 eram 45 universidades, já em 2011 além destas foram criadas mais 14 e estavam previstas mais 4, no ano de 2012 contava com 63 universidades Federais, ou seja, verificamos a expansão das Universidades que entre 2003 e 2012 foram criadas 18 novas Universidades Federais. Aproximadamente 140 novos campi foram criados e para o ano de 2013/2014 está prevista a criação de mais 27 campi.

A expansão do acesso por meio do REUNI, como asseveram Silva Júnior e Sguissardi (2012, p.23) que "se transformou em movimento que tem avançado a conta-gotas, com raros momentos mais significativos de expansão e mudança como o que ocorre agora com a implantação do REUNI". Com o intuito de mostrar esse processo apresentamos abaixo dados referentes ao acesso à educação superior no Brasil.

Conforme dados do INEP (2013) verificamos que as matrículas em cursos de graduação nas IFES passaram de 544.251 em 2003 para 849.679 em 2010, um aumento de 305.428 vagas. Esse movimento de expansão pode ser explicado não somente com base no processo de desenvolvimento econômico, mas também político e social.

Frente a isso percebemos que a fim de responder à pressão gerada na busca pela expansão da educação superior, o Estado tem reestruturado de forma a manter uma falsa

\footnotetext{
${ }^{3}$ O PingIFES é um projeto para o desenvolvimento de mecanismos de coleta de dados e padronização das informações provenientes das IFES de forma a disponibilizá-las em uma plataforma que as integre e as recupere de forma eficiente na SESu/MEC. Disponível em pingifes.mec.gov.br.
} 
democratização. Saviani (2010, p.14) afirma que:

\begin{abstract}
Ao longo do governo Lula, se por um lado se retomou certo nível de investimento nas universidades federais promovendo a expansão de vagas, a criação de novas instituições e a abertura de novos campi no âmbito do Programa "REUNI", por outro lado deu-se continuidade ao estímulo à iniciativa privada que acelerou o processo de expansão de vagas e de instituições recebendo alento adicional com o Programa "Universidade para todos", o PROUNI, um programa destinado à compra de vagas em instituições superiores privadas, o que veio a calhar diante do problema de vagas ociosas enfrentado por várias dessas instituições.
\end{abstract}

Nesse sentido, entendemos que o acesso à educação superior no Brasil ainda não foi universalizado de maneira a atender a todos com igualdade. No entanto, nas últimas décadas notamos um movimento no sentido de discutir a ampliação do acesso, bem como a proposta de políticas que visam inclusão social.

\title{
Considerações Finais
}

Procuramos, neste texto, dialogar com diversos autores, com vistas a proporcionar a análise do contexto social, econômico, cultural e ideológico em que as políticas educacionais em especial para educação superior são desenvolvidas. Assim, ao estudarmos a expansão da oferta de vagas na educação superior resultante do processo envolto ao REUNI, nos preocupamos em analisar a realidade que a envolve.

Assim, refletimos sobre as diretrizes neoliberais e a valorização do processo de mundialização do capital que influenciaram a política educacional brasileira nas últimas décadas. Tanto no governo FHC, quanto no governo Lula as políticas públicas foram desenvolvidas agregando-se, a partir de seus condicionantes, ao modelo de política do sistema capitalista. Como produto desse modelo de política neoliberal, verificamos por um longo período o sucateamento das universidades públicas e a expansão do ensino privado.

Consideramos que nos últimos anos a educação superior evidenciou, ainda que em termos numéricos, uma expressiva expansão, não podemos tratar tal expansão como um processo de democratização do acesso, pois, tendo em vista os dados citados anteriormente, isso não aconteceu de maneira efetiva. Nesse contexto, concordamos com o entendimento de Azevedo (2004) ao destacar que o que se evidenciou, foi um processo de "massificação", ou seja, expansão acompanhada da ampliação de vagas, mudanças no perfil da população atendida e, consequentemente, de construção de alternativas metodológicas e organizativas para esse nível educacional.

Verificamos ainda que, em contraste com as ações do governo FHC, que concebia a 
educação superior como um serviço não exclusivo, o governo Lula tem mostrado seu discurso ora como um bem público imbuído de função social ora enfatiza a necessidade do retorno econômico, pois ao mesmo tempo em que o discurso se baseia na democratização do acesso a educação superior pública, também se dá uma maior oferta de bolsas de estudos nas instituições privadas através de programas como PROUNI e FIES.

Destacamos que o governo Lula, apesar de guardar resquícios do modelo de gestão do governo FHC, no que tange à educação superior, combina um discurso que reconhece a importância, por meio do incentivo à expansão de IFES e a criação de vagas, não deixando de lado o caráter mercantilista e os interesses do capital.

Assim, a discussão referente à expansão da educação superior proposta pelo governo Lula por meio do REUNI, não está desvinculada de um processo social mais amplo, destacando o caráter estratégico e contraditório das políticas sociais, pois ao mesmo tempo em que se apresentada como mecanismo de democratização de oportunidades promovendo o desenvolvimento e a melhoria das condições de vida, bem como possibilidade de ascensão social, atende aos objetivos da produção e reprodução do capital e adequação às condições de competição no mercado além da certificação em massa e precarização da formação profissional e das condições de trabalho docente.

\title{
POLICIES OF HIGHER EDUCATION IN BRAZIL (2003-2010): DEMOCRATIZATION OR EXPANSION?
}

\begin{abstract}
The objective of this work is to discuss the process of expansion of higher education in Brazil. In this sense, we seek to review determining points and elements that characterize the Federal University Restructuring and Expansion Program Support Program (REUNI), reflecting on access to the public university. In order to do so, we present a brief discussion about State and public policies, especially policies for higher education, taking into account the established relationship between these elements and rescuing the determinants of this movement and its particularities. We sought to analyze educational policies focused on higher education during the Fernando Henrique Cardoso (FHC) and Lula government, in terms of access, as well as its guiding elements. This contextualization takes into account, that education can not be considered as a neutral phenomenon and, therefore, stems from the intervention of the State, and the effects of the space in which it is inserted. The analysis indicates that the process of reforms for higher education implemented in Brazil, mainly within REUNI is impregnated with ideological objectives, actions and contradictions that are established in relation to theoretical and practical presuppositions, presenting elements that at the same time result in the reform Of the state and seek to support social interests.
\end{abstract}

Key Words: Expansion; Democratization; higher education 


\section{Referências Bibliográficas}

AZEvedo, Janete. M. Lins de. A Educação como Política Pública. 3. ed. Campinas: Autores Associados, 2004.

APRILE, Maria Rita; BARONE, Rosa Elisa Mirra. Políticas Públicas para Acesso ao Ensino Superior e Inclusão no Mundo do Trabalho - o Programa Universidade para todos (PROUNI) em Questão. V Congresso Português de Sociologia. São Paulo, 2008. Disponível em: www.aps.pt/vicongresso/pdfs/182.pdf. Acesso em 12/08/2012.

BOITO JUNIOR, Armando. Hegemonia neoliberal e governo Lula. Revista Crítica Marxista. 2006, p.10-36. Disponível em: www.unicamp.br/cemarx/criticamarxista/critica17A-boito.pdf. Acesso em 04/3/2013.

BRASIL, Decreto $\mathrm{n}^{\circ} 6.096$ de 24 de abril de 2007. Programa de Apoio a Planos de Reestruturação e Expansão das Universidades Federais - REUNI. Presidência da República Federativa do Brasil. Brasília, 2007. Disponível em: http://www.planalto.gov.br/ccivil_03/_Ato2007-2010/2007/Decreto/D6096.htm. Acesso em $15 / 07 / 2012$.

BRASIL. Programa de Apoio a Planos de Reestruturação e Expansão das Universidades Federais - Relatório do Primeiro Ano. Brasília, 2008. Disponível em http://reuni.mec.gov.br. Acesso em 01/02/2013.

BRESSER PEREIRA, Luiz Carlos. A reforma gerencial de 1995. In: Cadernos Adenauer Burocracia e reforma do Estado. São Paulo: Fundação Konrad Adenauer, julho, 2001.

CATANI, Afrânio Mendes; OLIVEIRA, João Ferreira de. As políticas de diversificação e diferenciação da educação superior no Brasil: Alterações no sistema e nas universidades públicas. In: SGUISSARDI, Valdemar (org.). Educação Superior: velhos e novos desafios. São Paulo: Xamã, 2000. p. 63 a 81.

CUNHA, Luiz Antônio. O ensino superior no octênio FHC. Educação e Sociedade. Campinas, vol. 24, n. 82, p. 37-61. Campinas, 2003. Disponível em: http://www.scielo.br/pdf/es/v24n82/a03v24n82.pdf. Acesso em: 25/11/2012.

CARVALHO, Cristina Helena Almeida de. Política para o Ensino Superior no Brasil (19952006): Ruptura e continuidade nas relações entre o público e privado. In SILVA JR, João dos Reis, OLIVEIRA, João Ferreira de e Mancebo Deise (orgs.). Reforma Universitária: dimensões e perspectivas. p. 125-139. Campinas, SP: Editora Alínea, 2006.

DEITOS, Roberto Antonio. Políticas Públicas e educação: aspectos teóricos-ideológicos e socioeconômicos. In: Acta Scientiarum Education, Maringá: EDUEM, v.32, n.2, p. 209-218, 2010 .

FALEIROS, Vicente de Paula. O que é política social. São Paulo: Brasiliense, 2006.

FINATTI, Betty Elmer. Assistência Estudantil na Universidade Estadual de 
Londrina/UEL. 2007. Dissertação de Mestrado. Universidade Estadual de Londrina, Londrina.

INEP, Instituto Nacional de Estudos e Pesquisas Anísio Teixeira, 2013. Disponível em: http://www.inep.gov.br. Acesso em: 24/02/2013.

LIMA, Kátia Regina de Souza. Financiamento da Educação Superior Brasileira nos Anos do Neoliberalismo. In: SILVA JR, João dos Reis, OLIVEIRA, João Ferreira de e Mancebo Deise (orgs). Reforma Universitária: dimensões e perspectivas. p. 27-42. Campinas, SP: Editora Alínea, 2006.

Contra-reforma na educação superior: de FHC a Lula. São Paulo: Xamã, 2007.

NAGEL, Lizia Helena. O Estado Brasileiro e as políticas educacionais a partir dos anos 80. In: NOGUEIRA, Francys Mary Guimarães (org.). Estado e políticas sociais no Brasil. p. 99122. Cascavel: EDUNIOESTE, 2001.

OLIVEIRA, Dalila Andrade. As políticas educacionais no governo Lula: rupturas e permanências. Revista Brasileira de Política e Administração da Educação (RBPAE) - v.25, n.2, p.197-209, mai/ago. 2009. Acesso em 26/09/2012.

Disponível em http://seer.ufrgs.br/rbpae/article/view/19491/11317.

. Das políticas de Governo a política de Estado: reflexões sobre a atual agenda educacional Brasileira. Revista Educação e Sociedade. Campinas, v.32, n.115, p. 323-337, abr-jun. $2011 . \quad$ Disponível em: <http://www.scielo.br/pdf/es/v32n115/v32n115a05.pdf>. Acesso em 26/09/2012.

REUNI. Reestruturação e Expansão das Universidades Federais: Diretrizes Gerais. 2007. Disponível em: portal.mec.gov.br/sesu/arquivos/pdf/diretrizesreuni.pdf. Acesso em $16 / 04 / 2013$.

SAVIANI. Demerval. A Expansão do Ensino Superior no Brasil: Mudanças e Continuidades. Poíesis Pedagógica - v.8, n.2 ago/dez. 2010; p. 4-17. Disponível em: http://www.revistas.ufg.br/index.php/poiesis/article/view/14035/8876. Acesso em 28/05/2013.

SGUISSARDI, Valdemar. Diferenciação e diversificação: Marcas das políticas de educação superior no final do século. In: SGUISSARDI, Valdemar (org.). Educação Superior: velhos e novos desafios. P. 47 a 62. São Paulo: Xamã, 2000.

SHIROMA, Eneida Oto. Política Educacional. 4.ed. Rio de Janeiro: Lamparina, 2011.

SILVA JÚNIOR, João dos Reis; SGUISSARDI, Valdemar. Forma e razões da expansão da educação superior pública no Brasil. In: MANCEBO, Deise; BITTAR Mariluce; CHAVES, Vera Lúcia Jacob (orgs). Educação Superior: Expansão e Reformas educativas. Maringá: Eduem, 2012.

ZANARDINI, Isaura Mônica Souza. A ideologia da pós-modernidade e a política de gestão educacional brasileira. Tese de doutorado. Campinas, SP: UNICAMP/ Faculdade de Educação, 2006. 
Data de recebimento: 05/09/2014

Data de aceite: $24 / 04 / 2017$

\section{Sobre os autores:}

Adrian Alvarez é Doutor em Educação pela USP; Professor do Programa de Pós-graduação em Educação da Universidade Estadual do Oeste do Paraná. Endereço Eletrônico: adrianalvarez.estrada@gmail.com

Andressa Radaelli é Mestre em Educação pela UNIOESTE; Chefe de Coordenação Acadêmica da Universidade Federal da Fronteira Sul, Campus de Realeza. Endereço Eletrônico: andressaradaelli@ hotmail.com 